\title{
Patronage of traditional bonesetters in Makurdi, north-central Nigeria
}

\author{
This article was published in the following Dove Press journal: \\ Patient Preference and Adherence \\ 9 February 2015 \\ Number of times this article has been viewed
}

\author{
Ndubuisi OC Onyemaechi' \\ Omolade A Lasebikan ${ }^{2}$ \\ Itodo C Elachi ${ }^{3}$ \\ Sunday O Popoola ${ }^{4}$ \\ Kehinde S Oluwadiya ${ }^{4}$ \\ 'Department of Surgery, University \\ of Nigeria Teaching Hospital, \\ Ituku-Ozalla, Enugu, ${ }^{2}$ Department \\ of Orthopaedic Surgery, National \\ Orthopaedic Hospital, Enugu, \\ ${ }^{3}$ Department of Surgery, Benue State \\ University Teaching Hospital, Makurdi, \\ ${ }^{4}$ Department of Surgery, Ekiti \\ State University Teaching Hospital, \\ Ado-Ekiti, Nigeria
}

Background: Despite the numerous complications associated with traditional bonesetters' (TBS) practices, their patronage has remained high in developing countries. The aim was to study the reasons patients seek TBS treatment.

Methods: This was a descriptive hospital-based study of 120 patients who were treated by TBS. The sociodemographic profile of the patients, details of injuries sustained, reasons for TBS patronage, duration of TBS treatment, the number of TBS visited, the reason for abandoning TBS treatment, patients' belief about the TBS practice, and outcome of their treatment were studied.

Results: Out of 418 patients who presented with musculoskeletal injuries, 120 patients who had been treated by TBS before presentation met the inclusion criteria. The mean age of the patients was $37.4 \pm 10.5$ years. Advice of relatives and friends, as seen in $35(29.2 \%)$ patients, was the most common reason for TBS patronage. Other reasons were cheaper cost (number $[n]=30 ; 25 \%)$, sociocultural belief $(n=17 ; 14.2 \%)$, easy accessibility $(n=15 ; 12.5 \%)$, fear of amputation $(n=13 ; 108 \%)$, and fear of operation $(n=10 ; 8.3 \%)$. There was no correlation between these factors and age, marital status, occupation, and educational status $(P=0.41)$. Forty-two $(35 \%)$ patients believed TBS were not useful, a nuisance $(n=30 ; 25 \%)$, useful $(n=38 ; 31.7 \%)$, or indispensable $(\mathrm{n}=10 ; 8.3 \%)$. The opinion of patients about the outcome of TBS practice was: very satisfactory $(n=0 ; 0 \%)$; satisfactory but with deficiencies $(n=24 ; 20 \%)$; unsatisfactory $(n=80$; $66.7 \%)$; and no idea $(\mathrm{n}=16 ; 13.3 \%)$.

Conclusion: Advice of relatives and friends was the main reason for patronizing TBS. The majority of patients lost confidence in the TBS practice after patronizing them due to the high complication rate.

Keywords: utilization, traditional bonesetters, developing country

\section{Introduction}

Traditional bone setting is a well-recognized and age-long practice in Nigeria. In many developing countries, traditional bonesetters (TBS) still play a significant role in the primary treatment of fractures. ${ }^{1-4}$ In Nigeria, TBS provide about $70 \%-90 \%$ of primary fracture care in certain areas, ${ }^{5}$ and they enjoy high patronage and confidence in the society. ${ }^{1,6}$

Their patronage often cuts across social status, educational qualifications, and religious beliefs. There is a widespread belief in Nigerian society that TBS are better than orthodox practitioners in treating musculoskeletal injuries. ${ }^{1}$ Other reasons that may explain the popularity and patronage of TBS in Nigeria include easy accessibility, affordability, and familiarity, as reported by Nwachukwu et $\mathrm{al}^{7}$ (southeastern Nigeria). Ogunlusi et $\mathrm{al}^{8}$ and Oyebola ${ }^{9}$ (southwestern Nigeria) reported cultural beliefs, quicker and cheaper services, and fear of amputation at an orthodox hospital as the reasons for TBS patronage in their studies.
Correspondence: Ndubuisi OC Onyemaechi

Department of Surgery, University of Nigeria Teaching Hospital, Ituku-Ozalla Enugu, Nigeria

Tel +2348035504767

Email bisionyemaechi@yahoo.com 
The TBS's practice lacks the basic scientific knowledge of anatomy, physiology, radiology, and principles of infection prevention and control. As a result, it is associated with high failure rates and complications. ${ }^{3,4,6,10}$ These complications include acute compartment syndrome, nonunion, malunion, joint stiffness, contractures, chronic osteomyelitis, Volkmann's ischemic contracture, gangrene, and death. The health and socioeconomic consequences of these problems are enormous. These complications do not seem to deter other patients from patronizing the TBS..$^{11,12}$

Furthermore, despite the availability of modern orthopedic services in Nigeria, the TBS practice has continued to thrive. Superstition, ignorance, poverty, and pressure from relatives and friends have been described as the basis for this continued patronage despite the complications. ${ }^{2,8,11,12}$ There are very few studies on this subject from north-central Nigeria. Therefore, studying the behavior of patients that received TBS treatment and the reasons for the patronage in this region is a critical step in addressing the public health problems of TBS treatment in Nigeria holistically.

\section{Materials and methods}

This was a descriptive hospital-based study done at Federal Medical Centre, Makurdi, Benue State, Nigeria. Patients who sustained musculoskeletal injuries and had been treated by a TBS before presentation at the hospital formed the study population. A total of 132 patients presented at the Accident and Emergency department and at the orthopedic outpatient clinic of the hospital from January 2011-December 2011 after attending traditional bone setting centers. However, only 120 patients gave consent to participate in the study and were subsequently recruited.

The hospital is a 300-bed capacity tertiary institution in Makurdi, the capital city of Benue State, north-central Nigeria, and it serves a population of over 5 million people. Approval for this study was obtained from the hospital's research and ethics committee.

A structured observer-administered questionnaire was used to obtain information from the patients. The questionnaire was designed to address the research objectives and the validity was established after review by a panel of experts. It was pretested to ensure reliability for use in the study population. The data collected from the patients included age, sex, occupation, marital status, level of education, details of the initial injury, reasons for patronage of TBS, duration of TBS treatment, number of TBS centers visited, reason for abandoning the TBS treatment, patients' belief about the practice of TBS, and outcome of their treatment.
Table I Age distribution of the patients

\begin{tabular}{lll}
\hline Age group (years) & Frequency & Percent (\%) \\
\hline $0-10$ & 17 & 14.2 \\
$I I-20$ & 12 & 10.0 \\
$2 I-30$ & 19 & 15.8 \\
$3 I-40$ & 20 & 16.7 \\
$4 I-50$ & 15 & 12.5 \\
$5 I-60$ & 13 & 10.8 \\
$6 I-70$ & 15 & 12.5 \\
$7 \mid-80$ & 9 & 7.5 \\
Total & 120 & 100 \\
\hline
\end{tabular}

Data analysis was performed using SPSS (version 17). Test of significance was done using the Pearson's chi-square test. Statistical significance was set at a $P$-value $<0.05$.

\section{Results}

There were 418 patients who presented with musculoskeletal injuries within the study period; 132 of these patients had visited the TBS before presentation, giving a TBS attendance rate of $31.6 \%$. A total of 120 patients who consented to participate were studied. The age range was $3-80$ years with a mean age of $37.4 \pm 10.5$ years. Table 1 shows the age distribution of the patients. There were $84(70 \%)$ male and $36(30 \%)$ female patients. Fifty-five (45.8\%) patients were married, 52 (43.3\%) were single, ten (8.3\%) were widowed, while three $(2.5 \%)$ were separated. A total of 72 patients presented with complications of TBS treatment, giving a TBS complication rate of $60 \%$. Fifty-eight $(48.3 \%)$ of the patients were initially taken to the hospitals before they took their discharge to the TBS centers.

There were 31 (25.8\%) pupils/students, 21 (17.5\%) artisans, and $19(15.8 \%)$ traders. The others were ten $(8.3 \%)$ civil servants, 22 (18.3\%) farmers, and 17 (14.1\%) drivers, as shown in Table 2.

The educational status of the patients was as follows: primary education (number $[\mathrm{n}]=40 ; 33.3 \%$ ); secondary education $(n=37 ; 30.8 \%)$; tertiary education $(n=26 ; 21.7 \%)$; and no education ( $\mathrm{n}=17 ; 14.2 \%)$. Road traffic accidents was the cause of injury in $83(69.1 \%)$ patients. Others were falls

Table 2 Distribution of patients by occupation

\begin{tabular}{lll}
\hline Occupation & Frequency & Percent (\%) \\
\hline Civil servants & 10 & 15.0 \\
Pupils/students & 31 & 25.8 \\
Farmers & 22 & 15.0 \\
Drivers & 17 & 10.8 \\
Traders & 19 & 15.8 \\
Artisans & 21 & 17.5 \\
Total & 120 & 100 \\
\hline
\end{tabular}




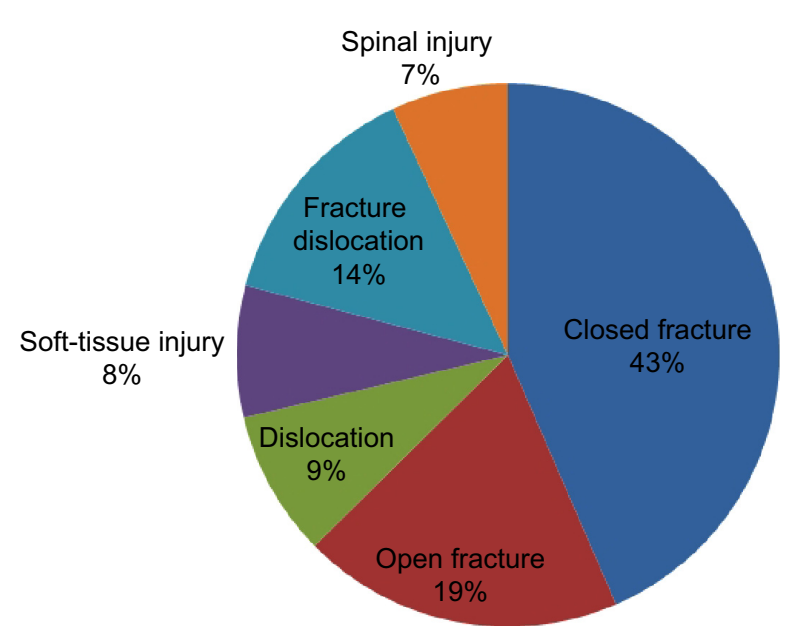

Figure I Types of injury among TBS attendants. Abbreviation: TBS, traditional bonesetters.

from height $(n=20 ; 16.7 \%)$, domestic falls $(n=13 ; 10.8 \%)$; and sports injuries $(n=4 ; 3.3 \%)$. Figure 1 shows the types of injuries sustained by the TBS attendants. The injuries sustained by the patients did not influence the reason to patronize TBS $(P=0.36)$.

The factors that influenced the decision to patronize the TBS (Table 3 ) are as follows: advice of relatives and friends $(\mathrm{n}=35 ; 29.2 \%)$; perceived cheaper cost of treatment $(\mathrm{n}=30$; $25 \%)$; sociocultural belief ( $\mathrm{n}=17 ; 14.2 \%$ ); easy accessibility $(\mathrm{n}=15 ; 12.5 \%)$; fear of amputation at the hospital $(\mathrm{n}=13$; $10.8 \%)$; and fear of operation $(\mathrm{n}=10 ; 8.3 \%)$. There was no correlation between these factors and age, marital status, occupation, and education $(P>0.05)$.

The majority of patients $(\mathrm{n}=72 ; 60 \%)$ visited only one TBS center, while $26(21.7 \%)$ and $22(18.3 \%)$ patients visited two and three TBS centers, respectively, before presenting to our hospital.

Only ten (8.3\%) patients believe that the TBS practice is indispensable. Thirty-eight (31.7\%) believe that TBS are useful, $42(35 \%)$ believe that they are not useful, and 30 (25\%) think they are a nuisance. The opinion of the patients about

Table 3 Factors that influenced the patients' decision to patronize TBS

\begin{tabular}{lll}
\hline Factors & Frequency & Percent (\%) \\
\hline Sociocultural belief & 17 & 14.2 \\
Advice of relatives/friends & 35 & 29.2 \\
Cheaper cost of treatment & 30 & 25.0 \\
Easy accessibility & 15 & 12.5 \\
Fear of operation & 10 & 8.3 \\
Fear of amputation & 13 & 10.8 \\
Total & 120 & 100 \\
\hline
\end{tabular}

Abbreviation: TBS, traditional bonesetters. the outcome of TBS treatment is as follows: very satisfactory $(\mathrm{n}=0 ; 0 \%)$; satisfactory but with deficiencies $(\mathrm{n}=24 ; 20 \%)$; unsatisfactory ( $\mathrm{n}=80 ; 66.7 \%)$; and no idea $(\mathrm{n}=16 ; 13.3 \%)$. Twelve (10\%) patients presented to hospital after they were discharged from TBS treatment, $48(40 \%)$ patients abandoned the TBS treatment because they were unsatisfied, while $60(50 \%)$ patients left because they developed complications. Age, marital status, occupation, and educational status did not seem to influence patients' beliefs about the usefulness of TBS practice and the outcome of their treatment $(P>0.05)$. However, patients who developed complications from TBS strongly disapproved of the TBS's practice and were dissatisfied with the outcome of their treatment $(P=0.001)$. The duration of TBS treatment ranged from 2-312 days with a mean of 94.5 days.

\section{Discussion}

In this study, $31.6 \%$ of patients that presented to hospital with musculoskeletal injuries had patronized the TBS centers before visiting the hospital. Solagberu ${ }^{2}$ reported a TBS attendance rate of $23.1 \%$ among patients with long bone fractures in Ilorin north-central Nigeria, while Ogunlusi et al ${ }^{8}$ (Ilesa, southwestern Nigeria) reported an attendance rate of $79.3 \%$. The high rate reported by the latter report may be due to the small sample size in their study and the sociocultural beliefs in southwestern Nigeria. The male preponderance $(70 \%)$ in this study, as in most trauma series, emphasizes the fact that males are predominantly injured due to their involvement in injury-prone activities. ${ }^{4,10,13}$

The mean age of the patients was $37.4 \pm 10.5$ years and the modal age group was $31-40$ years. This age group belongs to the productive age group of the society and implies that economic productivity may be adversely affected by TBS practice with attendant socioeconomic consequences. Studies have shown that this working population is most commonly involved in trauma; hence, they are most likely to patronize the bonesetters. ${ }^{4,10,13}$

It is interesting to note that $48.3 \%$ of the patients in this study were initially taken to hospitals before they eventually took their discharge to the bonesetters. This is comparable to reports by Solagberu ${ }^{2}$ (Ilorin, north-central Nigeria), OlaOlorun et $\mathrm{al}^{10}$ (Ogbomosho, southwestern Nigeria), and Dada et $\mathrm{a}^{13}$ (Lagos, southwestern Nigeria), where the incidence was $40 \%, 42 \%$, and $43 \%$, respectively. These were patients who probably had multisystem injuries, open fractures, or hemodynamic instability. They only waited for adequate resuscitation and stabilization in the hospitals before heading to the TBS. 
The students and pupils (25.8\%) were the largest occupational group. This was followed by farmers (18.3\%) and artisans (17.5\%). These patients are either financially dependent or low-income earners. This finding corroborates the reports by Aderibigbe et $\mathrm{a}^{12}$ and Dada et a ${ }^{13}$ whereby occupation and income level significantly influence the patronage of TBS.

The factors that influenced the decision to patronize the TBS were mainly the advice of relatives and friends and the perceived cheaper cost of TBS treatment. These factors were not limited to any particular sex, age group, occupational group, or education status $(P>0.05)$. Some authors have also reported the significant role played by relatives and neighbors in decision making regarding the patronage of TBS. ${ }^{2,13}$ The opinion of relatives and friends is an important factor in many African societies because of the existing social system. The communal lifestyle often involves relatives and friends contributing to defray the cost of treatment, as well as to suggest where treatment for ailments and injuries may be sought.

The cost of treatment was another important factor. Previous reports ${ }^{1,3,6,14}$ have highlighted the fact that the TBS treatment is believed to be cheaper by the patients. The majority (78.1\%) of the patients in this study were low-income earners. This finding supports previous reports that the income level of patients significantly influences the decision to patronize TBS. ${ }^{12,13}$ This group of people will find the payment in installments or in kind offered by TBS very attractive. An affordable and accessible trauma care service may help to discourage TBS patronage in developing countries.

Erroneous sociocultural beliefs in many African societies have contributed to the popularity of TBS practice in developing countries. The cultural belief that the TBS was superior to orthodox practitioners in treating fractures has been reported ${ }^{1,15}$ and accounted for $14.2 \%$ of TBS patronage in this study.

The fear of operation and amputation in the hospitals was responsible for $8.3 \%$ and $10.8 \%$ of TBS patronage, respectively. It is unfortunate to note that there are still erroneous beliefs in Nigeria that the only available option for treatment of fractures in hospital is amputation. . $^{1,811}$ There is a great need to educate the populace about modern orthopedic services in order to erase these wrong beliefs.

Most of the injuries treated by the TBS were closed injuries. This finding is similar to those of previous studies, ${ }^{2,4,13,14,16}$ and suggests that patients may be reluctant to visit the TBS when they have open wounds. Since TBS lack the basic principles of infection control in wound management, their intervention in the treatment of open fractures is bound to be associated with complications.

Forty-two (35\%) patients believe that the TBS are not useful, while $30(25 \%)$ patients consider them as a nuisance. Ten $(8.3 \%)$ patients think they are indispensable, while $38(31.7 \%)$ consider them useful. These findings are contrary to reports by Thanni ${ }^{1}$ (Shagamu, southwestern Nigeria) and Aderibigbe ${ }^{12}$ (Ilorin, north-central Nigeria), where the majority of their respondents believed that the TBS were very competent and indispensable. Furthermore, 80 (66.7\%) patients believe that the outcome of TBS practice is unsatisfactory. None considered the outcome very satisfactory; however, 24 (20\%) felt the outcome is satisfactory, but with some deficiencies. These findings are dissimilar to those of Thanni, ${ }^{1}$ where $43 \%$ of the subjects felt that the TBS were very competent with very satisfactory outcomes. While the subjects in this study were patients who had been to the TBS before presenting to the hospital due to complications or unsatisfactory outcomes, those in the studies by Thanni ${ }^{1}$ and Aderibigbe ${ }^{12}$ were ordinary members of society who did not have any experience with TBS practice. This difference in the study population may account for these contrary reports. These findings further highlight the misplaced trust and confidence that the populace has in TBS practice in Nigeria.

Age, occupation, and education did not seem to influence patients' beliefs about TBS practice and the outcomes of their treatment $(P=0.31)$. However, patients who abandoned the TBS because of complications strongly disapproved of their practice and treatment outcomes $(P=0.001)$. This disapproval was also seen among those who visited more than one TBS center $(P=0.03)$.

\section{Conclusion}

The patronage of TBS among patients who sustained musculoskeletal injuries was $31.6 \%$. The decision to visit TBS was influenced by the advice of relatives and friends. Other factors that encouraged the utilization of TBS were cheaper cost of treatment, sociocultural belief, easy accessibility, and fear of operation and amputation in the hospital.

There is a misplaced trust and confidence in the TBS practice in Nigeria because the majority of our patients believed that the TBS are not useful and that the outcomes of TBS's practice were not satisfactory after patronizing them. Educational status, occupation, and age did not influence the utilization of TBS. The provision of accessible and affordable orthopedic and trauma services, as well as health education, will reduce TBS patronage. 


\section{Acknowledgments}

The authors wish to acknowledge the assistance of the medical officers in the Orthopedic Surgery Unit - Dr Eze and Dr Edache Adejor - in the data collection.

\section{Disclosure}

The authors report no conflicts of interest in this work.

\section{References}

1. Thanni LO. Factors influencing patronage of traditional bone setters. West Afr J Med. 2000;19(3):220-224.

2. Solagberu BA. Long bone fractures treated by traditional bonesetters: a study of patients' behaviour. Trop Doct. 2005;35(2):106-108.

3. Onuminya JE. The role of the traditional bonesetter in primary fracture care in Nigeria. S Afr Med J. 2004;94(8):652-658.

4. Onyemaechi NOC, Onwuasoigwe O, Nwankwo OE, Schuh A, Popoola SO. Complications of musculoskeletal injuries treated by traditional bonesetters in a developing country. Indian Journal of Applied Research. 2014;4(3):313-316.

5. Omololu AB, Ogunlade SO, Gopaldasani VK. The practice of traditional bonesetting: training algorithm. Clin Orthop Relat Res. 2008;466(10): 2392-2398.

6. Oginni LM. The use of traditional fracture splint for bone setting. Nigerian Medical Practitioner. 1992;24(3):49-51.
7. Nwachukwu BU, Okwesili IC, Harris MB, Katz JN. Traditional bonesetters and contemporary orthopaedic fracture care in a developing nation: historical aspects, contemporary status and future directions. Open Orthop J. 2011;5:20-26.

8. Ogunlusi JD, Ikem IC, Oginni LM. Why patients patronize traditional bonesetters. Internet Journal of Orthopedic Surgery. 2007;4(2):1-7.

9. Oyebola DD. Yoruba traditional bonesetters: the practice of orthopaedics in a primitive setting in Nigeria. J Trauma. 1980;20(4):312-322.

10. OlaOlorun DA, Oladiran IO, Adeniran A. Complications of fracture treatment by traditional bonesetters in southwest Nigeria. Fam Pract. 2001;18(6):635-637.

11. Udosen AM, Otei OO, Onuba O. Role of traditional bone setters in Africa: experience in Calabar, Nigeria. Ann Afr Med. 2006;5(4):170-173.

12. Aderibigbe SA, Agaja SR, Bamidele JO. Determinants of utilization of traditional bone setters in Ilorin, north central Nigeria. J Prev Med Hyg. 2013;54(1):35-40.

13. Dada A, Giwa SO, Yinusa W, Ugbeye M, Gbadegesin S. Complications of treatment of musculoskeletal injuries by bone setters. West Afr J Med. 2009;28(1):43-47.

14. Onuminya JE, Onabowale BO, Obekpa PO, Ihezue CH. Traditional bone setter's gangrene. Int Orthop. 1999;23(2):111-112.

15. Orjioke CJG. Does traditional medicine have a place in primary health care? Orient Journal of Medicine. 1995;7(1 and 2):1-3.

16. Alonge TO, Dongo AE, Nottidge TE, Omololu AB, Ogunlade SO. Traditional bonesetters in south western Nigeria - friends or foes? West Afr J Med. 2004;23(1):81-84.
Patient Preference and Adherence

\section{Publish your work in this journal}

Patient Preference and Adherence is an international, peer-reviewed, open access journal that focuses on the growing importance of patient preference and adherence throughout the therapeutic continuum. Patient satisfaction, acceptability, quality of life, compliance, persistence and their role in developing new therapeutic modalities and compounds to optimize

\section{Dovepress}

clinical outcomes for existing disease states are major areas of interest for the journal. This journal has been accepted for indexing on PubMed Central. The manuscript management system is completely online and includes a very quick and fair peer-review system, which is all easy to use. Visit http://www. dovepress.com/testimonials.php to read real quotes from published authors. 